\title{
Grafomanías (y cómo pensar ciertas demandas culturales): del consumo a la escritura en la cultura masiva, Argentina 1920
}

\author{
Geraldine ROGERS \\ CONICET-Universidad Nacional de La Plata
}

\begin{abstract}
RESUMEN
Este artículo se propone registrar y determinar los alcances del proceso de democratización cultural centrado en la participación de los lectores de sectores amplios como productores de textos literarios en publicaciones periódicas argentinas de 1920. En segundo lugar, enfoca la relación entre las demandas emergentes de participación cultural con los discursos de los escritores profesionales y con las estrategias mercantiles de la industria cultural.
\end{abstract}

Palabras clave: publicaciones periódicas, Argentina 192, cultura masiva, literatura, democratización, demandas culturales, autorepresentación.

Graphomania (and how to think about emerging cultural demands): from consumption to writing in mass culture, Argentina 1920

\begin{abstract}
This article studies the scope of the cultural democratizing process, focusing in the involvement of readers from broad sectors of the population as producers of literary texts in Argentinean periodical publications in the 1920s. Secondly, it portrays the relationship the emerging demands for cultural participation had with a) the discourses of the professional writers, and b) the commercial strategies of the cultural industry.
\end{abstract}

Keywords: periodicals, Argentina 1920, mass culture, democratizing process, cultural demands, selfrepresentation.

SUMARIO: 1 .Introducción. 2.Escrituras de cualquiera. 3.Representarse a sí mismo. 4.Llamadas al orden. 5.Roberto Arlt, censor. 6.Cómo pensar ciertas demandas culturales.

No pueden representarse a sí mismos. K. Marx. El 18 Brumario de Luis Bonaparte 


\section{Introducción}

Actualmente, como en los inicios del siglo XX, se vive una etapa de intensa reconfiguración del campo de la cultura escrita que lleva a repensar, por ejemplo, cómo impacta en la cultura literaria la explosión de escrituras virtuales en la web, un espacio en que los consumidores se transforman fácilmente en productores, y donde la relativa masificación de la cultura digital superpone las categorías de escritor/editor, quitando casi cualquier restricción al significado de términos como "autor", "poeta" o "escritor" y haciendo más inciertos que antes los criterios de asignación de valor".

La "sobreproducción" de escrituras como resultado de cambios tecnológicos, de aspiraciones sociales (que incluyen la tendencia a apropiarse de los medios de producción) y de la "hipertrofia" del sistema de educación literaria formal e informal (Vanoli 149), la "pulsión a publicar", la combinación de los sesgos democratizantes y emancipatorios del fenómeno con la propensión al exhibicionismo y al deseo de transformarse en "microcelebrity" (150) -y por supuesto, con las muchas diferencias que corresponden a tiempos y fenómenos distintos-, son aspectos afines a los que merecieron reflexiones a comienzos del siglo anterior ${ }^{2}$. Tanto antes como ahora, términos como "sobreproducción" o "hipertrofia" hablan del desborde de ciertos límites y repartos que damos por sentado.

Toda demanda presenta reclamos a un determinado orden establecido. Ella está en relación peculiar con ese orden, que la ubica a la vez dentro y fuera de él (Laclau). El rico y diverso mundo de las demandas culturales en la Argentina de los años veinte ha sido muy poco estudiado. Intento a continuación relevar uno de sus aspectos: la aspiración de pasaje del consumo a la escritura, en un ámbito de la cultura impresa - diarios y revistas del circuito masivo en la década de 1920favorable a la comunicación de experiencias y al deseo de autorepresentación de los lectores. Se trata de un fenómeno relevante no sólo como indicio de las aspiraciones sociales emergentes sino también por el modo en que ellas fueron leídas y procesadas, tanto por el mercado como por zonas algo más restringidas de la cultura letrada.

1 "Finalmente, la cultura digital y la proliferación de artefactos de escritura en la web, sea en weblogs o en otras superficies digitales, hacen problemática la distinción entre aquellos textos que reclaman una lectura literaria y aquellos que no $\mathrm{y}$, lo más importante, modifican las formas de leer. La parcial democratización de los medios de publicación, entonces, traslada los criterios de legitimidad desde el experto hacia la masa, pero en un campo donde los productores son al mismo tiempo consumidores" (Vanoli, 2010:144).

${ }^{2}$ Sobre la abundancia de producción escrita y el deseo de publicar en la actualidad cfr. los artículos "Poesía actual y cualquierización" (Mazzoni y Selci, 2006) y "Sobre editoriales literarias y la reconfiguración de una cultura" (Vanoli, 2010). 


\section{Escrituras de cualquiera}

Desde 1900, revistas como Caras y Caretas contaban con secciones especiales para comentar los textos enviados por los lectores. A partir de 1920, Crítica -el diario "del pueblo y para el pueblo"- empezó a organizar concursos destinados a "payadores, milongueros, versificadores y poetas espontáneos". Un año antes, había iniciado los concursos de argumentos para cine y la publicación de notas sobre cómo redactar guiones; poco después abrió la sección especial "Ellas escriben" donde invitaba a las mujeres a transformarse en autoras.

En 1918 las revistas de teatro incluían sugerencias sobre "Cómo escribir una comedia" y organizaban competencias premiadas con su edición. En agosto de ese año, Bambalinas anunció un concurso de obras inéditas: las tres mejores, luego de ser evaluadas por un jurado encabezado por Armando Discépolo, serían publicadas por el semanario. Meses antes, La Escena había comunicado dos novedades sin duda relacionadas: su paso de la frecuencia quincenal a la semanal por el éxito de público y la invitación a mandar piezas de crítica teatral sobre los estrenos de cada semana. Incluso a través de la ironía -como en un texto que refería el caso de alguien que sin haber leído nunca obras de teatro deseaba escribir una en muy pocos días (B, 1918)- la creciente afición a ser autor se hacía evidente en las publicaciones periódicas, que mostraban como relativamente fácil el pasaje del consumo a la producción de textos ${ }^{3}$.

Horacio Quiroga, que en 1905 se había iniciado profesionalmente escribiendo para la revista más popular del mercado, mostró hasta qué punto se había expandido veinte años después la afición a transformarse en redactor, al publicar en 1925 en $E l$ Hogar un parcialmente irónico "manual al alcance de todos" y "trucos de oficio" para cuentistas aficionados.

También las revistas de canciones contaban con espacio para envíos de los lectores, que se volvían a su vez motivo de nuevos textos que los comentaban. En 1922 una nota de La Milonga Popular incluía fragmentos de correspondencia entre colaboradores que se imputaban mutuamente usurpación y "piratería" (LM, 1922a). Otra nota, de Canciones populares-Tangos, trataba sobre alguien acusado de plagio por haber mandado con su firma una poesía que incluía dos estrofas ajenas (LM, 1922b); el artículo incorporaba una detallada explicación sobre diferencias y similitudes entre las composiciones, y a continuación las publicaba para permitir la comparación y el deslinde de responsabilidades.

A veces se generaba un clima contencioso plagado de denuncias y escándalos relativos a estos asuntos, por lo visto de sumo interés y actualidad. Según Roberto Arlt, que poco antes había empezado a escribir en el diario más popular del mercado (Crítica) y en 1928 redactaba a sueldo una columna diaria en el más sobrio El Mundo, las controversias entre poetas de barrio -que mostraban sus versos,

\footnotetext{
${ }^{3}$ Empecé a tratar este tema en trabajos anteriores (Rogers, 2008 y 2013).
} 
fotografías y litigios en las páginas de "poesía popular" que abrían las revistas para la "colaboración espontánea"- se debían al mero interés de "figurar" (ElM, 1928b).

Al margen del tono despectivo, el diagnóstico no parece desacertado. Sin embargo, el hecho de que los problemas de autoría y derechos intelectuales fueran materia de discusiones en la que aparecían involucrados los lectores, muestra que los diarios y revistas "populares" no se agotaban en el consumo reproductor. Incorporaban al lector como figura activa y demandante: permiten imaginarlo componiendo y publicando relatos, letras de canciones, guiones para cine, piezas de teatro o de crítica teatral, y disputándose la propiedad de los textos. Los ejemplos abundan, y son indicio de una cultura masiva que intentaba sintonizar, interesadamente, con las demandas de un público dispuesto a desbordar el rol de mero consumidor al que parecía limitado por definición, reclamando para sí el derecho a transformarse en productores a través de la palabra escrita.

\section{Representarse a sí mismo}

Con el desarrollo de la industria cultural, la aspiración a desempeñar un oficio ligado a la escritura se combinó con el deseo de la gente de ser representada o, mejor aún, de representarse a sí misma.

En 1904 José María Ramos Mejía repudiaba la "tendencia al exhibicionismo" (155) fomentada por las páginas de la prensa popular. En efecto, la gente común comenzaba a anhelar ver sus composiciones, su imagen y su firma en las revistas y periódicos, privilegio hasta entonces reservado a los hombres eminentes.

Las publicaciones periódicas participaban de ese imaginario de visibilidad y pasaje. Aquello que hacía factible y deseable pasar de ser espectador a estar en el campo visual de los otros era afín a lo que posibilitaba el pasaje de la instancia de lector a la categoría de autor. Ambas cosas implicaban la fuga, aunque mas no fuera de manera acotada y efímera, al destino indiferenciado de consumidor anónimo, integrante de una masa donde -según una descripción contemporánea, de 1927- "ya no hay protagonistas: sólo hay coro", una aglomeración de individuos sin cualidad, de hombres en tanto no se diferencian de otros hombres (Ortega y Gasset, 1983: $41)^{4}$.

Las memorias de algunos escritores que consiguieron hacerse visibles en la década de 1920 dan cuenta de eso. Elías Castelnuovo relata su transformación de "persona desconocida" en individuo que inscribe un nombre propio en el espacio público, como en muchos otros casos, gracias a los concursos organizados por publicaciones periódicas:

\footnotetext{
4 “el hombre en cuanto no se diferencia de otros hombres, sino que repite en sí un tipo genérico" (Ortega y Gasset, 1983: 41).
} 


\begin{abstract}
Alentado por mi buena fortuna, remití sucesivamente tres cuentos a 'Nueva Era', otra revista a cargo de Alfredo R. Bufano, que tuvieron idéntica acogida. Debido a que nunca adjuntaba mi dirección en los envíos y encima cursaba la correspondencia con sobres de descarte del taller, que solían ostentar en la cabecera el membrete de alguna casa comercial, - un molino o una mueblería- el destinatario, ansioso de comunicarse con el autor, me escribía al molino o a la mueblería del membrete y su carta naturalmente le era restituida a vuelta de correo con la correspondiente indicación al dorso de 'Persona desconocida'. Cada vez más animado, envié un relato a un concurso realizado por el vespertino 'La Montaña', cuya sección de arte dirigía Juan Pedro Calou, conquistando el primer premio, y a continuación publiqué en 'Las Grandes Obras', semanario de literatura universal, otro relato más extenso: Notas de un literato naturalista. (109-110)
\end{abstract}

Francisco García Jiménez relata el "descubrimiento", parte de Gardel y Razzano, del poeta Celedonio Flores tras una firma encontrada en las "colaboraciones espontáneas" enviadas a un vespertino porteño:

\begin{abstract}
Allá por los años de la segunda década, la página de noticias policiales del diario nochero ' Ultima hora', que tenía sal y pimienta de pintoresquismo porteño, abría sus colaboraciones espontáneas en verso lunfardo, premiando a las publicadas con un billete de cinco pesos (nada despreciable entonces). Una noche aparecieron unos versos alejandrinos titulados 'Por la pinta', firmados con un lacónico seudónimo: Cele. Descarnados, directos, y sobre todo bien rimados: Desde lejos se te manya, pelandruna abacanada, que has nacido entre la mugre de un convento de arrabal... A Gardel y Razzano les gustaron y José Ricardo, el guitarrista del dúo, se largó a ponerles música de tango. Para formalizar el asunto indagaron quién era aquel escueto Cele, infructuosamente al principio. [...]. Cuando se dispuso a grabarlo en disco, la empresa fonográfica individualizó al autor, que resultó llamarse Celedonio Esteban Flores. Lo citaron al estudio de grabación, que estaba en los altos del cine Gran Splendid.
\end{abstract}

Según García Jiménez, se presentó a la cita un muchachito que le ofreció a Gardel otros versos, "era la letra de Mano a Mano..." (121-122). Eduardo Romano recuerda una situación parecida a propósito de Homero Manzi, quien en 1921, a los 14 años, envió sus estrofas al concurso de El alma que canta, comenzando así su vida pública como artista (Romano, 2007: 88). Esta clase de anécdotas abunda.

En Europa, Walter Benjamin observaba que, como parte de una transformación histórica del conjunto de los productos culturales, en el campo de la escritura comenzaba a desdibujarse la separación fija entre un escaso número de redactores y el amplio conjunto de los lectores (1989). Con la expansión de la prensa, una proporción cada vez mayor estaba en condiciones de pasar, aunque fuera ocasionalmente, del lado de los protagonistas o productores; y todo el mundo encontraba alguna vez la ocasión de publicar una composición, una experiencia o 
una opinión. La distinción entre autor y público perdía su carácter sistemático y se convertía en circunstancial, con lectores que podían pasar a ser redactores. El fenómeno era uno de los más relevantes de la cultura emergente.

El mercado cultural creaba expectativas de retribución económica y rápida fama. La incipiente profesionalización literaria y el origen social medio de los nuevos escritores alentaban la aspiración de pasar del consumo a la producción, con la oportunidad de adquirir nombre y reconocimiento ${ }^{5}$. El sustento de estas ilusiones era en parte real y en parte imaginario. La industria cultural, con sus representaciones ambivalentes, auspiciaba la idea de una paridad imaginaria entre productores y consumidores, estimulando la proliferación de autores aficionados, cuyas expectativas solían frustrarse tanto por carecer de las condiciones mínimas para desempeñarse en el oficio como por la sobreabundancia de redactores ${ }^{6}$.

Todo esto es indicio de las nuevas aspiraciones en un público amplio, dispuesto no sólo a apropiarse de cuanto material de lectura e imágenes circulaban, sino también a ejercer -aunque fuera de manera episódica y limitada- la autorepresentación y el derecho a la palabra, exigencia igualitaria que puede ser leída como demanda de "individualidad para todos" (Rancière, 2010a: 39). En ese sentido, Pablo Virno recupera una perspectiva que permite pensar lo masivo como instancia que, lejos de implicar siempre la decadencia o eclipse de lo individual, lo potencia cuando alguien de los muchos se personaliza (parcial y provisoriamente) a través de la experiencia pública:

La exposición a los ojos de los otros [...] ofrece al individuo la destreza para apropiarse de algún modo del anónimo 'se' del cual proviene, transformar en biografia inconfundible el Gattungswesen, 'la existencia genérica' de la especie. Contrariamente a cuanto sostenía Heidegger, es sólo en la esfera pública que se puede pasar del 'se' al 'sí mismo'. (30)

La exposición ante los otros y el intento de inscribirse como singularidad -a través de un trozo de escritura, un nombre, una imagen- puede leerse en la participación de los lectores como colaboradores en diarios y revistas ofrecidas como "populares". En medio de su trama de diestro cálculo comercial, el público podía imaginar para sí, en alguna medida, el papel de protagonista individual y escribiente. Esa participación combinaba verdad y simulacro: la oportunidad efectiva de presentarse a sí mismo, dar a conocer sus textos y comunicar experiencias, a partir de modestos saberes escolares o autodidactas, se combinaba con escenificaciones imaginarias de su representación:

${ }^{5}$ Hay pocas referencias a los autores aficionados en los años veinte (Sarlo 1985: 5175); (Pierini 2004: 73-98).

${ }^{6}$ Desarrollé este aspecto previamente (Rogers 2009). 
Historias de vida, concursos de relatos, crónicas y testimonios, talleres literarios con obreros y campesinos han buscado que el habla popular encuentre un sitio en el mundo escrito, que el discurso coloquial -pueblerino o de barrio- ingrese al campo "legítimo" de la cultura... [...] folcloristas, medios masivos y populistascontribuyen a veces a este proceso de hacer hablar al pueblo: recolectan narraciones, incluyen entrevistas callejeras en programas de radio y televisión, comparten con el pueblo los escenarios del poder. (García Canclini, 1992: 248)

La enmarañada trama del populismo de mercado $^{7}$ requiere prestar atención a las necesidades presuntamente falsas que la "ingeniosa máquina de distraer", juzgada tan engañosa como la "farsa" política ${ }^{8}$ alimentaba en una amplia capa de lectores, en nuevos escenarios en los que el "pueblo" aparecía no sólo representado sino también presentándose a sí mismo a través de innumerables colaboraciones individuales. En ese sentido, el espacio de autorepresentación que proveían las revistas y periódicos articulaba la expresión de demandas democráticas, que eran tales en la medida en que presentaban reclamos al orden establecido en el mundo de la letra impresa, y, -como se comprueba en las resistencias ofrecidas por las zonas más restringidas del circuito letrado-, tendían a correr los límites de ese orden.

En las páginas "populares", cualquiera podía aspirar a una firma y una imagen propia. En ese espacio impreso de la cultura mercantil, el derecho a una "individualidad para todos" se inscribía como derecho de poner en obra la capacidad de improvisar e imaginar, de dramatizar y parodiar, de poetizar y narrar, como capacidades que no pertenecían a ninguna clase particular sino a cualquiera, contestando la imagen, gastada pero muy vigente, del consumidor alienado por el torrente de palabras e imágenes, y seducido por las promesas falaces de la mercancía (Rancière, 2010a: 49).

\section{Llamadas al orden}

Desde el punto de vista de sus detractores, ese era uno de los efectos culturales de la "hiperdemocracia" (Ortega y Gasset): había demasiados individuos en condiciones de apropiarse de demasiadas palabras, imágenes y recursos. El motivo de preocupación era la apertura de esos espacios tan disponibles, capaces de darle a cualquiera la oportunidad de llevar a la práctica, aunque fuera parcialmente, sus demandas indiscriminadas de participación. La ansiedad provocada por el cambio

\footnotetext{
${ }^{7}$ Benjamin pensó en componentes utópicos y componentes cínicos, presentes a la vez en la cultura masiva (1999).

${ }^{8}$ Desde fines del siglo XIX y durante las primeras del XX el sufragio universal fue evaluado -no sólo por los conservadores sino también por sectores de izquierda- como un ardid destinado a manipular a una presa colectiva sugestionada y confusa: "si el pueblo entra todavía por algo en esta farsa política, lo hace ofuscado por las frases de charlatanes" decía el manifiesto electoral del socialismo en 1896.
} 
estructural en la cultura impresa de comienzos del siglo XX es bien conocida. En la década de 1930 Walter Benjamin evaluaba como "no progresista" el diagnóstico según el cual el porcentaje de desechos en la producción artística era, en esos años, mayor que nunca'.

En la Argentina la llamada "grafomanía" era objeto de observaciones científicas, críticas o sátiras que tomaban por objeto la sobreabundante afición a la escritura no sólo como "exhibicionismo de la palabra" propio de algunos genios (Bunge, 1928: 143), sino también como enfermedad popular.

En 1927 la revista Claridad llegó a proponer la supresión de derechos de autor con el fin de acabar con la proliferación de autores teatrales, esos "mercachifles atraídos por el olor del dinero [...] un sinnúmero de 'escritores' semi-analfabetos [...] algo denigrante y molesto para nuestras pretensiones de cultura" (C, 1927a). La revista de izquierda llamaba a la crítica a juzgar los valores artísticos y marcar el derrotero a sus artistas para contrarrestar el efecto del desastre ${ }^{10}$.

Por su parte, la reacción de los nuevos escritores profesionales fue ambivalente, como puede verse en el caso de Horacio Quiroga nombrado antes. Sin llegar a impugnar globalmente una democratización cultural de la que ellos mismos eran beneficiarios, los escritores reclamaron criterios para limitar la democracia sin ley que encontraba espacio en las publicaciones masivas, donde las letras quedaban libradas al saqueo de cualquiera.

\section{Roberto Arlt, censor}

Desde su página del diario El Mundo, el escritor periodista Roberto Arlt se dedicó a atacar a "la cáfila de escritorzuelos desocupados, recitadores de radio, compositores de tango y declamadoras profesionales..." (ElM, 1932), y a los autores improvisados alentados por los concursos abiertos de composiciones "Para

${ }^{9}$ El diagnóstico citado era de Aldous Huxley (1933): "Las técnicas reproductivas y las rotativas en la prensa han posibilitado una multiplicación imprevisible del escrito y de la imagen. La instrucción escolar generalizada y los salarios relativamente altos han creado un público muy grande capaz de leer y de procurarse material de lectura y de imágenes. [...] Ahora bien, el talento artístico es muy raro; de ello se sigue... que en todo tiempo y lugar una parte preponderante de la producción artística ha sido minusvalente. Pero hoy el porcentaje de desechos en el conjunto de la producci6n artística es mayor que nunca... Estamos frente a una simple cuestión de aritmética. [...]. La situaci6n puede resumirse de la manera siguiente. Por cada página que hace cien años se publicaba impresa con escritura e imágenes, se publican hoy veinte, si no cien. [...] Resulta por tanto que, tanto hablando en términos absolutos como en términos relativos, la producción de desechos es en todas las artes mayor que antes; y así seguirá siendo mientras las gentes continúen con su consumo desproporcionado de material de lectura, de imágenes y sonoro.” (Benjamin, 1989: 42).

${ }^{10}$ Traté las relaciones entre revistas de izquierda y mercado cultural en la década de 1920 en dos trabajos anteriores (Rogers, 2012 y 2013). 
autores noveles de ambos sexos" o certámenes de letras para tangos en los que el lector podía participar no sólo como competidor sino incluso como jurado. En 1928 escribe:

Hay que leer Alma que canta o cualquiera de esas revistas destinadas a la difusión de la letra de los tangos. Prima un romanticismo de almacén y todo va tan falseado que lo ridículo de estas composiciones sólo puede satisfacer el alma de fabriqueras analfabetas y de vagos ídem, ídem. Y si todavía ese romanticismo estuviera cargado de un poco de belleza, vaya y pase. Pero allí todo está cargado de grosería, de cosas tan inmediatas y repulsivas a veces que son de imposible reproducción. Y lo que ocurre es esto: que los compositores de letras son unos burros. Esa es la verdad. En cambio, cuando interviene un artista, la cuestión cambia de inmediato. (ElM, 1928a)

El argumento de Arlt era interesado: presentaba su posición como escritor que, aunque redactara en un periódico, era ante todo un artista ${ }^{11}$. Dos años después, sigue:

Salvo dos o tres autores de tango, el resto de los letristas hacen coplas verdaderamente infames [...]. El tango gira en torno de la vida del pobre. En la existencia del pobre, lo más anormal es quizá el amor y la traición en el amor. El hombre se gana la vida trabajando [...] y ni tiempo para respirar le queda. Pretender que gente así se dedique al amor, es pedir gollerías. Que se hagan traición, una estupidez [...] el vago que no tiene nada que hacer [...] agarra la guitarra $\mathrm{y}$, si tiene un poco de imaginación, empieza a hilvanar coplas. [...] El pueblo repite los malos versos. No analiza. Bueno ¿quién analiza aquí? Y los copleros escriben. (ElM, 1930)

Estos fragmentos muestran el presupuesto de desigualdad que ordena el mundo de las letras, fijando los límites dentro de los cuales los diferentes tipos de inteligencias actúan, designando qué temas pueden tratar unos pero no otros, y qué prácticas de escritura tienen derecho a reclamar un espacio (Rancière 2010b). Dan por descontado que los pobres carecen de tiempo e interés para cantar el amor traicionado, que los copleros escriben por falta de mejor ocupación, y, una vez más, que el pueblo se limita a repetir pésimos versos.

En el revoltijo de composiciones rechazadas, Arlt desechaba un tango de Enrique Santos Discépolo más tarde convertido en clásico ${ }^{12}$. Pero lo que importa acá no es la falla en la asignación de valor literario, comprobable sólo desde una fácil posterioridad (que nos permitiría listar además una suma de firmas y

${ }^{11}$ En un trabajo previo traté los conflictos de competencia y de jerarquización de la escritura planteados en la Argentina por los escritores-periodistas hacia 1900 (Rogers, 2010).

12 "Esta noche me emborracho" (1928). 
composiciones que emergieron de ese sistema de revistas y concursos, y que integran ahora el canon de la cultura argentina) ${ }^{13}$. No es la falta de acierto en el pronóstico lo que interesa, sino hacer visible un orden literario que, incluso desde la columna de un diario, se resistía a ser asaltado por demandas de participación de los cualquiera, que envalentonados por saberes improvisados y por espacios abiertos a sus prácticas de escritura en las revistas y periódicos masivos, desbordaban a cada paso y de manera notable el rol de consumidores pasivos que, paradójicamente, se les achacaba.

En abril de 1928, en una nota titulada "Poeta de parroquia", Roberto Arlt ridiculizaba a los escribientes de barrio con pretensiones de poeta. Los cargos eran aspiración indebida y exhibicionismo; la responsabilidad, de las revistas que alentaban la grafomanía:

Por lo general, el vate es uno de esos sujetos que han hecho todos los oficios y que escriben en las páginas de 'poesía popular' que todas las revistas tienen como desaguadero de la 'colaboración espontánea' y destinadas a la mentalidad más pobre del público [...]. Por lo general, el autor se ha hecho hacer una fotografía que ilustra a los lectores sobre las bellezas físicas del vate, y de cómo esa belleza física que él encarece en el retrato es el reflejo de su inspiración de 'pueta'. (ElM, 1928b)

La incorrección gramatical enfatizaba la torpeza de quien ensayaba prácticas literarias para las que no contaba con la capacidad mínima. El absurdo rebasaba los límites cuando estos 'puetas' emprendían discusiones intelectuales:

Yo, que leo hasta los periódicos de Villadiablo, donde aparecen poemas que son obras maestras de la estupidez, me he reído siempre al leer estas controversias donde dos fulanos desbarran que es un contento [...]. Siempre me he dedicado a seguir estas controversias, al final he visto que los charlatanes eran dos vates de barrio que sólo discutían para poder figurar.

¡Figurar!... Esa es la necesidad terrible y angustiosa del hombre cuya madre o esposa lee en la carnicería de barrio el poema que publicó 'la sección de poesía popular'. (ElM, 1928b)

\section{Cómo pensar ciertas demandas culturales}

Quisiera terminar proponiendo un marco posible para estudiar lo implicado en ese pasaje del consumo a la producción de escritura. El carácter complejo y no unilateral de la cultura masiva fue indagado por W. Benjamin, S. Kracauer, R. Williams, S. Hall, Martín Barbero y García Canclini, entre otros. Una perspectiva

${ }^{13}$ Es el caso de nombres como los de Pascual Contursi, Homero Manzi o Celedonio Flores, por nombrar algunos de los que hoy figuran en la antología 200 años de poesía argentina, editada en 2010 (Monteleone). 
que incorpore esos aportes -así como los de J. Rancière sobre las capacidades intelectuales y los presupuestos de desigualdad- será una mirada que, sin desconocer las estrategias manipulatorias de la industria cultural-, pueda explorar también las demandas emergentes a las que ella puede haber dado curso.

La legítima aspiración de apropiarse de los medios de producción (en este caso, la escritura) fue usada por espacios de la cultura impresa que estimulaban aspiraciones legítimas a través de representaciones ilusorias o ambivalentes ${ }^{14}$.

En la Argentina, tanto las demandas de participación cultural como las impugnaciones de que fue objeto, no pueden separarse del proceso de democratización política que estaba teniendo lugar en esos mismos años. Tanto la nueva institucionalidad -instaurada en 1916 a partir de la nueva ley de sufragio ${ }^{15}$ como la industria cultural en expansión fueron mecanismos de agenciamiento -de construcción y captura- de "lo popular", que aunque no significaran la realización plena de los derechos que ahí se expresaban, hicieron posible la emergencia de demandas.

En este marco, tampoco las críticas al cambio político pueden ser separadas de las que apuntaban contra espacios que daban curso a la palabra escrita de obreros semiletrados y letristas de coplas "verdaderamente infames" (ElM, 1930). En 1916 Leopoldo Lugones protestaba contra las ilusiones creadas por la "falacia del sufragio" que daba al pueblo engañado "la ilusión de soberanía" (142). Quince años después, Roberto Arlt dejaba asentado: "Yo no creo en la democracia. Lo he dicho un montón de veces, y en eso coincidimos el general y yo" (ElM, 1931).

Opiniones parecidas lamentaban las ilusiones que la promesa democrática y mercantil activaba incesantemente en el público. La "grafomanía" amenazaba la jerarquización y control de aquello a lo que las publicaciones masivas, interesadamente, daban curso: la tendencia colectiva a traspasar los límites establecidos y buscar protagonismo.

Las demandas culturales asoman en el cinismo manipulador del mercado como contracara que da a leer aspiraciones a medias articuladas, que emergen en el preciso momento en que son suprimidas. Se trata entonces de vislumbrar esa apenas-emergencia justo antes de su captura por el mercado, pero también antes de su aprobación o descarte por parte de los jueces culturales.

14 En la década de 1930 europea ese componente utópico fue aprovechado por la industria cultural y por el fascismo (Benjamin, 1989).

${ }^{15}$ La puesta en práctica de la Ley Sáenz Peña, dictada en febrero de 1912, llevó a la presidencia a Hipólito Yrigoyen en 1916. La llamada "ley de sufragio universal", instauró la obligatoriedad y el carácter secreto del voto, lo que redujo las posibilidades de manipulación electoral por parte de los aparatos políticos y expandió notablemente el número de quienes hacían uso efectivo del derecho de sufragio (Sábato, 2010). 
La posibilidad de entrever algo de eso supone detenerse en objetos poco razonables e incluso hipotéticos, como las inclinaciones literarias de "fabriqueras analfabetas" o compositores "burros", para conjeturar qué impulsos inventivos podrían haber intentado materializarse en sus malas coplas, o de qué modo alguien de la masa anónima podría haber querido eludir la condena de inercia y consumo, mediante unas líneas donde poner a prueba sus vulnerables capacidades y donde estampar una firma configuradora de singularidad. Vislumbrar cómo a través de una destartalada colaboración, acompañada de un nombre y a veces de una foto, cualquiera de los muchos lograba al fin personalizarse, aunque fuera provisoriamente, y alcanzaba la experiencia de hacerse visible ante los otros como uno, consiguiendo en las páginas de las revistas transformar en nombre propio o biografía particular una existencia genérica.

Relevar estos aspectos no apuntaría a rehabilitar elementos bajos ni a adjudicar valor a objetos rechazados. Por el contrario, implicaría dejar de lado metódicamente los criterios de valor, suspender transitoriamente las reglas de preselección que sirven para separar los desechos en la producción artística, para, antes de aplicar cualquier criterio de valor, dar cuenta en primer lugar de la mera existencia de esos deseos, condenados de antemano a borrarse en el campo visual de una investigación que en lo masivo no pudiera ver otra cosa que la reproducción y la mudez indiferenciada del consumo.

La política -nos dice Rancière- comienza precisamente cuando ciertos repartos son desestabilizados. Como el que separa a quienes podrían poetizar el amor y la traición de aquellos en quienes esa pretensión resulta ridícula, el que divide de manera indudable a lectores de escritores, a consumidores de productores, a grafomanías de escrituras. Cuando por ejemplo esos que no tienen tiempo o medios para escribir se toman el tiempo que no poseen, y se apropian de los medios que encuentran a mano, para probar que pueden ser escribientes -y participar como tales en un mundo común-, y no condenados al consumo ciego o al adiestramiento.

La dimensión política de las demandas culturales podría radicar entonces en su disposición para confirmar o disputar la distribución de espacios, identidades y competencias de escritura. Implicaría también repensar el vínculo paradójico entre literatura y democracia, en la medida en que, por ejemplo, un autor como Roberto Arlt, empeñado en construir su autoimagen como recién llegado al mundo de las letras, y que se definía en las páginas de El Mundo como un igual entre iguales -"un hombre de la calle, de barrio, como usted y como tantos que andan por ahí" (ElM, 1928c)- podía sostener a la vez la necesidad de un orden razonable que mantuviera a raya la avalancha de quienes, con sus ilimitadas demandas de pasaje a la producción y el protagonismo, parecían querer imponer la capacidad que no importa quién de apropiarse de una escritura liberada de tutela.

Se trata de elementos indispensables para comprender algo más de la nada simple circulación cultural. Pensar los fenómenos de identificación y reconocimiento que están en la base de la cultura masiva requiere miradas que, 
además de manipulación, permitan ver otra cosa en ciertas demandas emergentes que, tanto en el pasado como en el presente, ahí suelen tener curso.

\section{BIBLIOGRAFÍA}

BENJAMIN, Walter.

1989 "La obra de arte en la época de su reproductividad técnica", en Discursos interrumpidos I. Buenos Aires: Taurus.

1999 "Grandville o las exposiciones universales", en Poesía y capitalismo. Madrid: Taurus.

1998 "El autor como productor", en Iluminaciones III. Tentativas sobre Brecht. Madrid: Taurus.

BUNGE, Carlos O.

1928 Tratado general de Pedagogía 3. Teoría de la educación. Madrid: Espasa-Calpe.

CASTELNUOVO, Elías.

1974 Memorias. Buenos Aires: Ediciones Culturales Argentinas. GARCÍA CANCLINI, Néstor.

1992 Culturas híbridas. Estrategias para entrar y salir de la modernidad. Buenos Aires: Sudamericana.

GARCÍA JIMÉNEZ, Francisco.

1964 El tango. Historia de medio siglo (1880-1930). Buenos Aires: Eudeba.

LACLAU, Ernesto.

2007 "La denigración de las masas", en La razón populista. Buenos Aires: Fondo de Cultura Económica, pp. 15-91.

LUGONES, Leopoldo.

1991 El payador. Caracas: Biblioteca Ayacucho.

MAZZONI, Ana y SELCI, Damián.

2006 "Poesía actual y cualquierización", en Jorge Fondebrider (comp.), Tres décadas de poesía argentina. 1976-2006. Buenos Aires: Libros del Rojas, pp. 257-268.

MONTELEONE, Jorge (sel. y pról.).

2010200 años de poesía argentina. Buenos Aires: Alfaguara.

ORTEGA Y GASSET, José.

1983 La rebelión de las masas. Barcelona: Ediciones Orbis. PIERINI, Margarita.

2004 "Los autores de La Novela Semanal. Cruces y tensiones en la ampliación del campo literario", en La Novela semanal (Buenos Aires, 1917-1927). Un proyecto editorial para la ciudad moderna. Madrid: CSIC, pp. 73-98. 
RAMOS MEJÍA, José María.

1904 Los simuladores del talento en las luchas por la personalidad y la vida. Barcelona: Maucci.

RANCIÈRE, Jacques.

2010a "Las desventuras del pensamiento crítico", en El espectador emancipado. Buenos Aires: Manantial, pp. 29-52.

$2010 \mathrm{~b}$ La noche de los proletarios: archivos del sueño obrero. Buenos Aires: Tinta Limón.

ROGERS, Geraldine.

2008 "Arte y crítica plebeya", en Caras y Caretas. Cultura, política y espectáculo en los inicios del siglo XX argentino. La Plata: Edulp, pp. 253-324.

2010 "Émile Zola en los textos porteños de Rubén Darío: una autoimagen de los escritores modernos en la Argentina finisecular", Anales de Literatura Hispanoamericana, vol. 39, Madrid, 2010, pp. 173-189.

2012 "Strife for 'the popular': Claridad against avant-garde writers in Critica (Argentina, 1926-1927)", Dossier: Between folk and highbrow: popular culture and its functions in avantgarde magazines of the 1920s and 1930s. PhiN. Philologie im Netz.

2013 "Sufragio cultural: lo masivo en revistas argentinas en 1920", Iberoamericana. América Latina-España-Portugal, Instituto Iberoamericano de Berlín, (en prensa).

ROMANO, Eduardo (coord. y pról.).

2007 Las letras del tango. Antología cronológica 1900-1980. Rosario: Fundación A. Ross.

SÁBATO, Hilda.

2010 Pueblo y política. La construcción de la Argentina moderna. Buenos Aires: Capital Intelectual.

SARLO, Beatriz.

1985 El imperio de los sentimientos. Narraciones de circulación periódica en la Argentina (1917-1927). Buenos Aires: Catálogos Editora.

VANOLI, Hernán.

2010 "Sobre editoriales literarias y la reconfiguración de una cultura", Nueva Sociedad, $\mathrm{n}^{\circ}$ 230, noviembre-diciembre de 2010, pp. 129151.

VIRNO, Paolo.

2011 "Multitud e individuación”, Confines 27 (2011), pp. 24-31. 


\section{De publicaciones periódicas de Buenos Aires:}

La Escena.

Bambalinas.

E 1918a: "Aviso", nº. 3, 18 de julio de 1918, sin p.

B 1918a: "Carta abierta", no. 3, 16 de abril de 1918, sin p. La Milonga.

LM 1922a: "Ladrones literarios. Acusados y acusadores", no. 16, 1922.

LM 1922b: "Un lector que protesta", nº 17, 1922. El Hogar.

EH 1925a: Quiroga, Horacio. "El manual del perfecto cuentista", nº 808, 10 de abril de 1925.

EH 1925b: Quiroga, Horacio. "Los 'Trucs' del perfecto cuentista", $\mathrm{n}^{\circ} .814$, 22 de mayo de 1925.

Claridad.

C 1927a: "Por los teatros", no. 138, 10 de julio de 1927. El Mundo.

ElM 1928a: Arlt, Roberto. "Música y poesía populares", 3 de noviembre de 1928, p. 4.

ElM 1928b: Arlt, Roberto. "Poeta de parroquia", 7 de noviembre de 1928, p. 4.

ElM 1928c: Arlt, Roberto. "La crónica n 231", 31 de diciembre de 1928, p.4.

ElM 1930: Arlt, Roberto. "La traición en el tango", 4 de diciembre de 1930, p. 4.

ElM 1931: Arlt, Roberto "Del que vota en blanco", 23 de abril de 1931, p.4. ElM 1932: Arlt, Roberto. "Algo más sobre el gaucho", 5 de diciembre de 1932, p. 4. 